\title{
Forward to the Special Section: In an Era of Transnational Migration
}

\author{
Kerry Richter ${ }^{1}$
}

This special section includes articles presented at the fourth Mahidol Migration Center Conference held in June 2016. The theme of the conference, In an Era of Transnational Migration, elicited papers on a number of themes. Broadly, these include migrant status and well-being; migrants as distinct demographic groups; and migration policy. The conference also included a number of papers covering cross-cutting issues. Three of the conference papers are presented in this section, representing a cross-section of these pertinent themes.

Keywords: transnational migration; migration conference; migration policy; migrant wellbeing.

The Mahidol Migration Center held its fourth conference at Salaya from 28 to 30 June 2016. The theme, In an Era of Transnational Migration, was intended to draw papers on a wide variety of topics from multiple continents. Besides the presentation of research studies and thematic reviews, the conference featured several panel discussions on current topics in transnational migration.

The themes of the papers clustered around three main areas. First, migrant status and well-being was investigated by several participants. These papers examined migrant assimilation and integration into the host society; discrimination and its cost of discrimination to migrants and employers; migrant health; the impact of natural disasters on migrants; and the special situation of stateless populations.

The second unifying theme of the conference was an explicit attempt to examine migrants within demographic groups: specifically, children, women, families, and the aged. Child migrants include those who migrate independently and those who migrate with their families. Children are also affected when their parents migrate, either internally or transnationally, and they are "left behind" with other family members. Women migrants often face special circumstances: they are more likely to have informal work or to not be working, making them dependent on a spouse or other working family members. Researchers have paid little attention to the circumstances of families who are affected by migration, including families left behind by migrants who are dependent on remittances. Also, when the focus is on migrant workers, the lives of accompanying family members are often forgotten. The aged are of particular concern, as they often no longer live near their adult children and may increasingly be called upon to care for grandchildren.

The third main theme examined by conference participants was that of national and regional migration policies. These papers covered the prospects for revised migration

\footnotetext{
${ }^{1}$ Mahidol University, Salaya, Thailand. Email: kerry.ric@mahidol.ac.th
} 
policies under ASEAN; policies for skilled workers in China, Singapore, Malaysia, and Thailand; methods for achieving zero irregular migration in Malaysia; and the effect of migrant policies on migrant education and multiculturalism.

Finally, the conference also included papers that focused on cross-cutting issues. Networking was discussed as an important feature of the migrant experience, both in terms of information flow for potential migrants and as an important way for to maintain social ties. The idea of using existing social networks as a method to reach migrants on policy changes and other issues that affect them was also promoted. Another major cross-cutting theme at the conference was multiculturalism and its interaction with policy. Some participants raised the point that it is not clear whether migrants, and host societies, actually want multiculturalism. Many migrants keep their own language and culture, with one example being European retirees in Thailand who form enclaves and continue to speak their own language. The issue of what to call migrants was also raised; as migrants are increasingly recognized as an important part of the economy, the use of terms such as "aliens" or even racial terms become less common. Finally, participants discussed how migrants become change agents both in their sending and receiving communities, and how this is a useful perspective to examine how the transnationalism process takes place.

\section{Papers in the special section}

We are pleased to present three of the papers presented at the conference in this special section of JPSS. Roy Huijsmans' paper re-examines how young migrants have been viewed in past research, and makes the point that the way that age is conceptualized has a strong impact on research perspectives. While viewing children and adolescents as a separate group is somewhat new, the expanding research on this group has recognized the complexity of the issue. While children and teenagers certainly migrate with other family members, they are also often independent, and may migrate long distances or simply cross a border every day for economic reasons. This view of young migrants as independent agents is an important part of the overall migration picture, though concern about their exploitation by brokers and employers is warranted as well.

In the second article in the section, Mahbub Alam Prodip provides little-known information about the situation of Rohingya migrants from Myanmar who are living in Bangladesh. He reviews the policy decisions enacted by the two governments over the past decades that have pushed the Rohingya population out of Myanmar, and that continue to affect the Rohingya population left behind. Prodip also gives an overview of the health and educational programs provided for children in the refugee camps, and analyzes whether their status is improved with this migration.

Choo Chin Low and Khairiah Salwa Mokhtar's article examines Malaysia's recent shift to the implementation of "deportation turn" policies, following a global trend. The paper outlines how Malaysia plans to reach its goal of "zero illegal immigrants" by 2020 . The costs involved in enforcing these policies include investments in the legal, 
human resource and physical infrastructure capacity of detention centers and in immigration forces. Additionally, increased diplomatic efforts are needed to involve other regional governments in cooperation with this policy.

These papers give a good representation of the timeliness of the issues discussed at the conference, and of their complexity. As citizens and governments increasingly develop a transnational perspective, research efforts must keep pace to aid in our understanding of the changing situation. The MMC conference series has provided a forum for those concerned with migration to share their latest thinking on these issues, as the three papers in this issue illustrate. 